\title{
A soja e Phakopsora pachyrhizi sobrevivem durante o pousio de inverno em Mato Grosso?
}

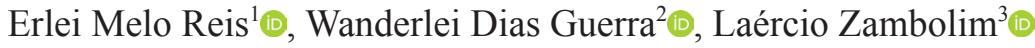

${ }^{1}$ Instituto Agris, Rua Miguel Vargas, 291, CEP: 99025-380, Passo Fundo, RS, Brasil. ${ }^{2}$ Aprosoja- MT. Associação dos produtores de milho e soja de Mato Grosso, Rua Eng. Edgar Prado Arze, 1.777 - Centro Político Administrativo, CEP 78049-932, Cuiabá, MT, Brasil. ${ }^{3}$ Universidade Federal de Viçosa, Av. Peter Henry Rolfs, s/n, CEP: 36570-900. Campus Universitário, Viçosa, MG, Brasil

Endereço para correspondência: Erlei Melo Reis (erleireis@upf.br)

Data de chegada: 30/12/2020. Aceito para publicação em: 12/05/2021.

$10.1590 / 0100-5405 / 247106$

No Brasil, a soja [Glycine max (L.) Merr.] é cultivada desde o Rio Grande do Sul até ao norte no Amapá e do Oeste em Roraima ao leste no Maranhão ampliando a época de cultivo e o período de soja verde no campo.

Phakopsora pachyrhizi Sydow \& Sydow (11), o fungo agente causal, é um parasita obrigado ao parasitismo, ou biotrófico, tendo como característica de sobreviver pela colonização de plantas da família Fabaceae (10). O fungo, portanto, não sobrevive em sementes e em restos culturais da soja seu principal hospedeiro. Desse modo, o fungo só existe onde a soja está presente fazendo com que a cultura dessa leguminosa seja desejável na safra normal de cultivo e indesejável na entressafra.

\section{Conceitos básicos}

Meio ambiente em biologia, inclui tudo o que afeta diretamente o metabolismo ou o comportamento de um ser vivo, incluindo a luz, o ar, a água, o solo ou os outros seres vivos que com ele coabitam (1).

Clima é o conjunto de condições meteorológicas (elementos: temperatura, precipitação pluvial, vento, umidade do ar, pressão do ar) típicas do estado médio da atmosfera num determinado ponto da superfície terrestre (1).

Tempo é o estado físico da atmosfera em um determinado momento e local (1).

Planta voluntária, guaxa ou tiguera. Referem-se as plantas de soja originadas de grãos do cultivo anterior, que germinam voluntariamente em qualquer lugar, sem ter sido intensionalmente semeada, crescendo sem cuidado.

Os grãos que caem ao solo durante a colheita e transporte havendo água suficiente, germinam dando origem a plantas voluntárias. Essas plantas, em alta população, são comuns por alguns dias e, mais tarde, pela redução das chuvas, sua população é reduzida ou eliminada.

Soja invasora ou soja daninha. Por conceito, o termo erva daninha é usado para designar qualquer planta superior que interfira nos interesses do homem e do meio ambiente (7). Nesse texto é usado para as plantas voluntárias de soja presentes em meio aos demais cultivos anuais como por exemplo em lavouras algodão. Lembra-se que estas plantas de soja completam o seu ciclo antes do algodão, sofrem debulha, mas devido ao déficit hídrico raramente germinam originando uma nova geração.

Ponte-verde. O termo é aplicado às plantas de soja em lavouras, áreas experimentais, plantas voluntárias de soja, ou soja invasora de lavouras cultivadas, infectadas por $P$. pachyrhizi na entre safra garantindo o inóculo de junho a setembro nas lavouras de soja em Mato Grosso e, portanto, a introdução do patógeno nas lavouras da próxima safra.

Pousio de inverno ou descanso da terra cultivada. É a prática agrícola que consiste em deixar a área cultivada sem cultivo, ou apenas com vegetação voluntária, durante pelo menos um período em que uma cultura comercial seria tradicionalmente cultivada (5).

Ponto de murcha permanente. É definido como o conteúdo de água de um solo no qual as folhas de uma planta que nele crescem atingem, pela primeira vez, um murchamento irreversível, mesmo quando colocada em atmosfera saturada com vapor de água (2). Em soja, Procópio et al. (8) relataram que o ponto de murcha permanente ocorreu quando a tensão de água no solo cultivado com soja, em dois estádios fenológicos foi de 283,41 (pré-florescimento) e 283,01 $\mathrm{kPa}$ (início do enchimento de grãos). O déficit hídrico ocorrente no estado deve resultar na morte da soja quando no solo a tensão de água atinge esses valores.

Necessidade hídrica da soja. Contribuindo para o entendimento do reflexo do pousio de inverno na sobrevivência da soja apresentam-se informações sobre o consumo de água pela cultura. O requerimento hídrico para a máxima produtividade da soja é de 450 a $700 \mathrm{~mm}$ bem distribuídos durante o ciclo da soja (3), ou ainda, necessita de 7 a $8 \mathrm{~mm}$ de água por dia (4). Se essa exigência de água não for satisfeita e o teor de água no solo atingir o ponto de murcha permanente a planta morre.

A semente de soja necessita absorver no mínimo 50\% de seu peso em água para assegurar boa germinaçao e os maiores rendimentos da soja em Londrina, PR, foram obtidos com precipitação pluvial de 650 a $700 \mathrm{~mm}(3,4)$.

Segundo a Classificação climática de Köeppen, o clima em Mato Grosso é o Aw (clima de savana) tropical quente, com estação seca de inverno e precipitação pluvial média anual de $1.665 \mathrm{~mm}$ (Tabela 1). Nesse clima as plantas de ciclo anual (soja, miho, feijão, algodão, girassol e etc.) são cultivadas na estação das águas com precipitação de setembro a maio de $1629,6 \mathrm{~mm}$ no período de 1977 a 2006 (6). Por isso, a safra de verão é limitada à estação com chuvas a partir de 15 de setembro se estendendo até maio.

A intensidade do déficit hídrico durante o pousio de inverno é documentada nos dados do número de dias com chuva, média mensal, em Mato Grosso, no período de 29 anos. No período dos três meses mais secos, o número de dias com chuva foi inferior a 2,5 (Fig. 1).

O pousio natural de inverno se estende de junho a agosto 


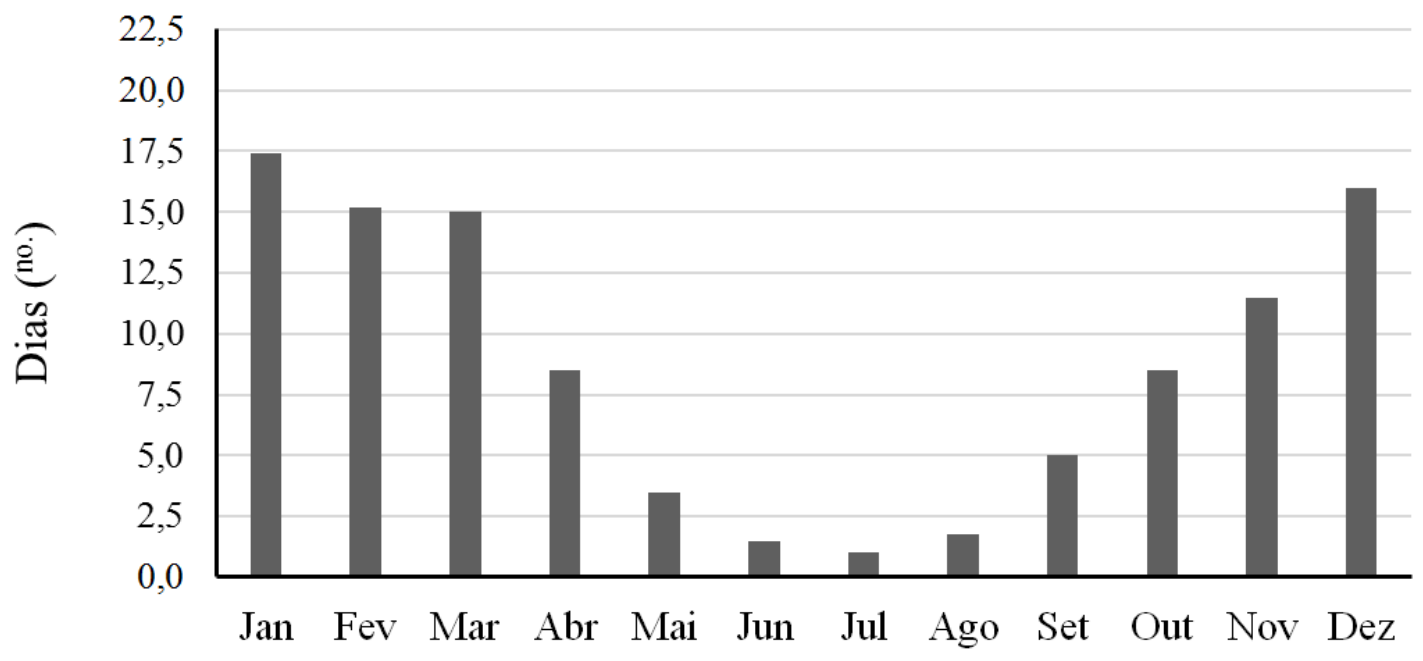

Figura 1. Número de dias com chuva em Mato Grosso no período de 1977 a 2006. Médias mensais. Fonte: Modificado de Marcuzzo (7).

com uma precipitação pluvial de $35,4 \mathrm{~mm}$ em 90 dias (Tabela 1). Portanto, o cultivo de plantas anuais nesse período somente é possível com o uso da irrigação.

Tabela 1. Precipitação pluvial $(\mathrm{mm})$ total mensal e anual da média histórica no período de 1977 a 2006 no Cerrado de Mato Grosso

\begin{tabular}{lc}
\hline Mês & Média \\
\hline Janeiro & 297,6 \\
Fevereiro & 244,0 \\
Março & 237,6 \\
Abril & 119,2 \\
Maio & 43,5 \\
Junho & $\mathbf{1 3 , 6}$ \\
Julho & $\mathbf{6 , 7}$ \\
Agosto & $\mathbf{1 5 , 1}$ \\
Setembro & 66,1 \\
Outubro & 136,1 \\
Novembro & 204,4 \\
Dezembro & 280,9 \\
\hline Total anual & $1.665,0$ \\
\hline
\end{tabular}

Fonte: Modificado de Marcuzzo (7).

Sobrevivência de Phakopsora pachyrhizi em Mato Grosso. Devido ao déficit hídrico nos meses de junho a agosto, impedindo a vegetação da soja, revisam-se os mecanismos de sobrevivência de $P$. pachyrhizi.

Sendo $P$. pachyrhizi, fungo biotrófico e obrigado ao parasitismo, o principal mecanismo de sobrevivência é a colonização de plantas vivas de soja. Desse fato resulta a exigência do fungo da presença de plantas de soja vegetando durante o pousio de inverno e com duração do molhamento foliar diário para garantir o processo infeccioso.

Hospedeiros alternativos. Nenhum relato, com prova de patogenicidade, foi encontrado na literatura consultada de sua presença em Mato Grosso, quer sejam plantas anuais ou perenes (9). No entanto, Yorinori et al. (12) citam que a planta Desmodium purpureum (Mill.) Fawc. \& Rendle, popularmente conhecida como beiço-de-boi, uma planta daninha comum em todas as lavouras de soja nas regiões Centro Oeste e Sul do Brasil, é também hospedeira alternativa de $P$. pachyrhizi.

No sul do Brasil tem sido citados o kudzu [Pueraria lobata (Willd.) Ohwi.] e a soja perene [Neotonia witwigii (Wight \& Arn.) Lackey] (9).

Não foram encontrados relatos científicos, com prova de patogenicidade, sobre os hospedeiros alternativos de $P$. pachyrhizi em Mato Grosso.

Plantas guaxas, tiguera ou voluntárias. No estado, a extensão, ou a população e a área com plantas voluntárias ao longo de rodovias, estradas, carreadores e bordas de lavouras, é facilmente visível. Sua sobrevivência na entressafra é dependente da disponibilidade hídrica. Essas plantas de soja tem sido documentadas em áreas urbanas no período de junho a setembro com reduzida presença de sintomas ou sinais da ferrugem a medida que o déficit hídrico avança durante o pousio de inverno. É provável que essas plantas, embora infectadas, não cumpram sua função de pontes-verdes, por serem eliminadas ou pelas condições climáticas adversas (falta de molhamento folhar para a infecção) antes de 15 de setembro.

Plantas de soja invasoras ou soja daninha. Estas plantas também podem exercer a função de pontes-verdes com a manutenção e multiplicação do inóculo [invasoras sensu Pitelli (8)]. São citadas como exemplo, as presentes em lavouras de algodão, crotalária, feijão, milho e etc. Estas plantas também acabam sendo eliminadas durante ou, a depender do ciclo da cultura, no final do pousio de inverno.

A intensidade do déficit hídrico imposto pelo pousio de inverno tem potencial para eliminar toda e qualquer planta anual das lavouras em Mato Grosso? Se sim, provavelmente não desempenham papel epidemiológico sendo eliminadas nesse período e não assegurando o inóculo para a próxima safra, mas algumas plantas sobrevivem sob o efeito da iluminação das cidades e podem manter esporos de $P$. pachyrhizi.

Tem sido aceito que a principal fonte de inóculo da ferrugem da soja, em Mato Grosso, são as pontes-verdes da leguminosa. Todavia, nessa carta levanta-se a hipótese de que a soja guaxa, a soja invasora, 
funcionando como pontes-verdes podem ser eliminadas pelo pousio de inverno, apesar de ainda haver plantas vivas especialmente nas cidades, mas sem comprovação da viabilidade infectiva dos esporos existentes.

Finalmente, se a hipótese da inexistência de inóculo para desencadear epidemias anuais da ferrugem da soja em Mato Grosso, for verdadeira, de onde vem o inóculo?

\section{REFERENCIAS}

1. Ayoade, J.O. Introdução à climatologia para os trópicos. Rio de Janeiro: Bertrand Brasil, 1996. 332p.

2. Briggs, L.J.; Shantz, H.L. The wilting coefficient for different plants and its indirect determination. Washington: Department of Agriculture, 1912. 83p. (Bulletin, 230).

3. FAO. Yield response to water. Roma: FAO, 1986. (FAO Irrigation and Drainage Paper, 33).

4. Farias, J.R.B.; Nepomuceno, A.L.; Neumaier, N. Ecofisiologia da soja. Londrina: 2007. (Embrpa, circular Técnica, 48).
5. Haas, H. J., Willis, W. O., \& Bond, J. J. (1974). Summer fallow in the western United States (USDA-ARS. Conserv. Res. Rep. No. 17). U.S. Gov. Print Office, Washington, DC.

6. Marcuzzo, F. F. N., Cardoso, M. R. D., \& Faria, T. G. (2012). Chuvas no Cerrado da região Centro-Oeste do Brasil: análise histórica e tendência futura - DOI 10.5216/ag.v6i2.15234. Ateliê Geográfico, 6(2), 112-130. https://doi.org/10.5216/ag.v6i2.15234

7. Pitelli, R.A. O termo planta-daninha. Planta Daninha, Viçosa, v.33, n.3, p.inicial-final, 2015.

8. Procópio, S.O.; Santos, J.B.; Silva, A.A.; Donagemma, G.K.; Mendonça, E.S. Ponto de murcha permanente de soja, feijão e plantas daninhas. Planta Daninha, Viçosa, v.22. n.1, p.35-41, 2004.

9. Reis, E.M. Sobre os hospedeiros de Phakopsora pachyrhizi, no Brasil. Summa Phytopathologica, Botucatu, v.45, n.1, p.113, 2019.

10. Slaminko, T.L.; Miles, M.R.; Frederick, R.D.; Bonde, M.R.; Hartman, G.L. New legume hosts of Phakopsora pachyrhizi based on greenhouse evaluations. Plant Disease, St. Paul, v. 92, n.5, p.767-771, 2008.

11. Sydow, H.; Sydow, P. A contribution to knowledge of parasitic fungi of the island of Formosa. Annales Mycologici, Berlin, v.12, p.108, 1914.

12. Yorinori, J.T.; Nunes Junior, J.; Lazzarotto, J.J. Ferrugem "asiática" da soja no Brasil: evolução, importância econômica e controle. Londrina: Embrapa Soja, 2004. 40p. 